\title{
DEUS MACHI DE JORGE GUZMÁN
}

\author{
Cedomil Goic \\ Domingo Faustino Sarmiento Emeritus Professor \\ The University of Michigan \\ cgoic@vtr.net
}

La novela que hoy nos interesa es Deus machi (Santiago: LOM Ediciones, 2010. 212

p. (Colección Narrativa), de Jorge Guzmán.

\section{ADVERTENCIA PREVIA}

El libro se acompaña de una 'advertencia previa', como nota preliminar del autor, en la que se nos informa que:

"Si el lector reconoce los componentes históricos de esta narración (y los hay por cientos), reconocerá al mismo tiempo que han sido falsificados para servir intenciones narrativas. Espero que el texto lo justifique, porque no se trata de una novela histórica, sino simplemente de una novela" [7].

Las falsificaciones o ficciones de los componentes históricos de esta narración se desarrollan de un modo menos ironizante que las expresas burlas de las falsedades de la historia en Ay, mama Inés, cuando juega con los lugares de nacimiento o las formas de la muerte de Pedro de Valdivia, y el planteamiento, no mencionado, por cierto, de Hayden White de la ficción de la historiografía, en el marco de la llamada nueva novela histórica o nueva crónica histórica hispanoamericana.

El silenciamiento de las fechas en el relato no impide situarse ni reconocer el contexto histórico-social de fines del siglo XVI y comienzos del siglo XVII gracias a los acontecimientos que aluden a hechos reconocibles.

Entre los componentes históricos puede encontrarse la noticia, en el capítulo III, de la muerte del Gobernador, alusión que remite, aparentemente, a la muerte de Martín García Oñez de Loyola, en el desastre de Curalaba, en 1598, quien fue el único Gobernador muerto en la guerra, después de Pedro de Valdivia. Esto nos sitúa a fines del siglo XVI. 
Este acontecimiento desastroso marcó al Bío-Bío como límite fronterizo y trajo como consecuencia la destrucción de las ciudades del sur.

El nombre del gobernador Alonso de Acosta, inexistente en el historial de los gobernadores del Reino de Chile, recuerda al de Alonso de Ribera, que gobernó en dos períodos, de 1601 a 1605 y de 1612 a 1617 . La omisión del nombre de los gobernadores y la mención de Alonso de Acosta, cubre y sustituye el nombre de una veintena de gobernadores en los primeros cincuenta años del siglo XVII.

Entre los datos implícitos o aludidos están la orden en 1608 por Real Cédula de Felipe III de la esclavización del indio prisionero de guerra y la institución por los jesuitas del salario familiar para indios de servicio; las referencias a la Real Audiencia, instaurada en Chile en 1609; la guerra defensiva, que se inició en 1612, con la presencia y la dirección del padre Luis de Valdivia y se suspendió la aplicación de la Real Cédula sobre la esclavitud de los indios prisioneros de guerra que el Gobierno de García de Ramón (1605-1610) había decretado en 1608. Queda así mismo clara la oposición de los encomenderos a la guerra defensiva del P. Luis de Valdivia.

En 1625, una Real Cédula de Felipe IV ordenó la guerra ofensiva y la esclavización del indio prisionero de guerra.

La oposición de los encomenderos a la guerra defensiva del P. Valdivia y a la prohibición del servicio personal y de la esclavitud es una característica del período, fuertemente marcada, que la novela destaca. Lo fue igualmente el rechazo de las 'derramas' o contribuciones que a lo largo de los siglos XVI, XVII y XVIII debieron pagar los encomenderos, sujetos a la imposición renovada de las tasas, como se las llamó en la época: la Tasa de Santillán (1561), la Tasa de Gamboa (1580), la Tasa de Esquilache (1621), la Tasa Real (1622) y la Tasa José Laso de la Vega (1721), hasta que Ambrosio O’Higgins suprimió la encomienda, en 1791, y se crearon los pueblos de indios regidos por sacerdotes.

¿Cuáles son, ahora, las falsificaciones más precisas o ficciones para servir “intenciones narrativas"?

Las hay, diríamos, de varios tipos. Entre las más obvias está la deformación del nombre de Fray Luis de Valdivia, por Luis de Saldivia, como el padre de la 'guerra defensiva'. Otra, es el nombre del cacique Anganamón, el protector de Fray Lorenzo, que lo conduce sano y salvo al rescate. Nombre que coincide con el del cacique que marca el inicio de la guerra defensiva con la muerte violenta de tres jesuitas en Elicura, en 1612, para vengar el paso de dos de sus mujeres al bando cristiano.

Otro dato histórico apunta a la presencia de una familia de apellido germánico. No hubo encomenderos de apellido Richter, pero sí de otros apellidos germánicos: Blume y Lisperguer. En este caso, vemos Richter, en lugar de Lisperguer. Los nombres de Catalina, Agueda nos acercan alusivamente a la familia de Catalina de los Ríos y Lisperger, la Quintrala, en la novela solo Catalinita, la pequeña que jugaba con sus criados indios, cabalgando y azotando con una varilla a su criada Guacolda; el de Gonzalo de Los Lagos, en lugar de Gonzalo de los Ríos; el nombre de Juan Rodolfo Richter en vez de Juan Rodulfo Lisperguer, soldado muerto en combate y esposo de Ana Luisa; la posesión de la hacienda de El Ingenio, en la Ligua. Todas son alusiones directas a datos históricamente definidos. 
Talvez la mas importante y decisiva falsificación en la novela es la invención del protagonista de la serie principal, el alumbrado o iluminado Fray Lorenzo de Argomedo. La experiencia del alumbrado tiene una significación trascendental en la novela y la descripción de cada acontecimiento visionario posee una imaginativa elaboración que marca los momentos definidores del relato. Digamos que hubo en Chile movimientos de alumbrados, con sus manifestaciones más notables hacia el siglo XVII y comienzos del XVIII. Se trataba de individuos o sectas heréticas orientadas hacia la contemplación de visiones místicas o ilusiones visionarias y sensuales. En el caso del joven Lorenzo, su experiencia en el Mihrab de la Mezquita Catedral de Córdoba genera una visión luminosa marcada por el encuentro de dos mundos - cristiano y musulmán-y la seducción de lo extraño o de lo otro, que se convertirá en la matriz del relato de su vida, amplificado en pasos de errancia, entre cavilaciones, rechazos y aceptaciones, extrañamientos e identificaciones, para rematar en una conclusión que ofrece la suma de una experiencia herética que quiere callar y ocultar en una escritura cabalística. El temor lo conduce a limitar su actividad educativa a la enseñanza de la gramática latina y la retórica. Fray Lorenzo no ha prestado atención al consejo de San Ignacio de Loyola en sus Ejercicios espirituales que señala que el sacerdote debiera 'huir de cosas extraordinarias'. Santa Teresa, Fray Luis de León, San Juan de la Cruz y otros sufrieron las consecuencias de la singularidad de sus notables experiencias y obras místicas y religiosas. En la novela, la 'lujuria espiritual' de sor Leocadia, monja de la familia Richter, no carece de antecedentes en la literatura de las monjas en Chile, pero ancla fundamentalmente en las referencias a los místicos españoles, particularmente a Santa Teresa de Jesús.

En el plano del lenguaje, se da otra aparente 'falsificación' en el uso de dos voces nahuas. 'Tiánguez', del Nahua tianguis, mercado indígena, de uso en México, pero también en Ecuador -obsoleto-y Perú, y extrañamente para mí, para designar también el mercado indígena vecino a la Plaza de Armas de Santiago, como lo consigna una acta del Cabildo de Santiago. La otra voz es 'tamales', para referirse a las humitas o humintas, que parece desplazar el uso mapuche y chileno, sin explicación; talvez pretendiendo ampliar el marco de lectores y la recepción de la obra. Pero, como ha observado el autor, la voz tamales puede encontrarse en el Cautiverio feliz de Pineda y Bascuñán.

En un gesto diferente, el narrador emplea regularmente la expresión 'mapuche' para el enunciado en singular o plural, el o la mapuche y los o las mapuche, contra la norma de la lengua española. Esta última característica del lenguaje parece definir una posición fronteriza que tendrá otras consecuencias en la obra.

En otro plano, las visiones extraordinarias, milagrosas o chamánicas, de españoles o indios se asocian a los ejemplos del P. Alonso de Ovalle, en su Histórica relación del Reino de Chile (1646) y otros. Sometidas en su tiempo a la 'Protestación del Autor', declaración en que este se somete a la autoridad de la Iglesia en materias de fe y milagros u otros portentos, como la levitación de seres humanos y de objetos, descritos desde un punto de vista español o indígena. En la novela se exponen directamente como formas de la experiencia del mundo o mundos representados y de su cultura.

La novela, en la serie narrativa de fray Lorenzo, tiene como subtexto el famoso exemplum, parte narrativa autobiográfica del tratado Cautiverio feliz, de Francisco Núñez de Pineda y Bascuñán, que relata la experiencia del soldado como cautivo del 
cacique Maulicán. La diferencia fundamental reside en que en la novela de Guzmán el relato no es la historia de un joven soldado prisionero, sino de un misionero jesuita en manos de un cacique. En ambos relatos, se trata de un cautivo cautivado por su señor y por la vida y las costumbres de los indios: la percepción inquietante de la poligamia y la libre sexualidad, el baño de hombres y mujeres desnudos, la ausencia aparente de conflictos internos y de sentimiento de culpa. Igualmente, en ambos relatos, se desarrolla la resistencia de los personajes a la seducción, la práctica de la oración, la autopunición o autoflagelación y el arrepentimiento.

En el relato de Pineda y Bascuñán, el joven soldado resiste hasta el fin la tentación de la carne, a pesar de la vecindad de los cuerpos en la misma ruca y la cercanía de los lechos. En este caso, en Cautiverio feliz, se dan las formas del tratado y del manejo de variados tipos de discurso, como argumentos judiciales, deliberativos y suasorios, para explicar la razón de las guerras dilatadas de Chile. En la novela, se trata de una experiencia biográfica ficticia en el marco de una visión iluminada del mundo. En ambas, se procede en la tensión de seguridad y peligro, con la protección provista por su amo, marchando hacia el rescate, bajo el asedio constante de un cacique cordillerano, que quiere darle muerte. El rescate final será feliz a pesar de las numerosas dificultades humanas y naturales: entre estas, el cruce de ríos y corrientes peligrosas y la amenaza permanente de sus perseguidores mapuches que andan en procura de su muerte.

'La tentación invencible', el instinto sexual, propone diferencias entre el soldado cautivo, que la combate y no cede a su poder, a pesar de la juventud del prisionero, lo que sirve para ilustrar la virtud del cautivo. En Fray Lorenzo, a pesar de su condición sacerdotal, resistencia, oraciones y autoflagelación, termina por ceder al rito de la mañunga por la joven mapuche que lo ama. Al menos parcialmente, porque el rito debía completarse con el robo o rapto de la joven, al cual el sacerdote se niega. Todo ello no le impedirá recordar, en su ancianidad, con ternura a la joven mapuche.

\section{EL TITULO}

Detengámonos por un momento en el título de la obra: Deus machi. Se da la unión de dos sustantivos, uno en latín y el otro en lengua mapuche, que producen un instantáneo impacto a todo lector. ¿Qué es esto? Los títulos de las novelas llevan por lo general el nombre de un personaje, femenino o masculino, un dicho o frase que designa algo, un objeto, un lugar, un tiempo, una misión, un hecho, la modalidad de algo. Si nos ponemos en el plano de lo sagrado podría verse aquí la contraposición del Deus cristiano y del machi mapuche en una tensión de oposiciones que nos recuerda el título de otra novela de Guzmán, Job-boj. Elaborada esta como una palabra y su palindromo, su lectura al revés, y su imagen en el espejo separadas por un guión. En el título de Deus machi, falta el guión o la barra que pudiera proponérnoslo como una contraposición. Lo que induce inevitablemente a pensar que no es así sino más bien una palabra modificada por la otra como su adjetivo. Sin embargo, al mismo tiempo, por qué no ver la contradicción entre los dos términos como dos opuestos culturalmente significativos que remiten, cuando entramos en la lectura de la obra, a las dos series narrativas de que se compone: una, 
la hispánica y chilena, su fe y su política cristiana; la otra, la mapuche y la práctica del machi curandero o curandera.

El título provoca así una dificultad e intriga al lector. Pero veamos la portada del libro.

La portada representa la imagen escultórica de un sacerdote dividida vertical y simétricamente en dos bandas de colores diferentes: una verde con la representación difuminada del mundo indígena y otra gris azulada del mundo cristiano y sus símbolos. Imagen del hibridismo, la mezcla de dos mundos, que despliega la novela.

Si atendemos, ahora, al título y a la disposición de la novela, se nos abren algunas formas más claras. La disposición de la novela ordena dos series narrativas alternadas, y al mismo tiempo opuestas o contrastadas.

En la novela contemporánea universal esta disposición responde a una novedosa ordenación planteada originalmente por el novelista argentino Eduardo Mallea, Fiesta en noviembre (1938) y por el norteamericano William Faulkner, Wild Palms (1939), que contrapone dos relatos diferentes como representación de términos opuestos. Jorge Guzmán utilizó esta clase de disposición en su primera novela Job-boj que une dos series contrapuestas, continuas y alternadas. En este caso, numeradas una en números árabes y la otra en romanos, sin títulos ni argumentos ni otros encabezamientos, correspondientes cada una a escenarios diferentes y a tiempos o momentos distintos de la vida del mismo personaje.

En Deus machi la ordenación numérica de veinte capítulos es continua en números romanos, sin títulos ni argumentos, y contempla una introducción y una conclusión. Estas características afectan a los capítulos inicial y final, alejados en el tiempo y en el espacio, capítulos I y XX, que narran el comienzo y el fin de la experiencia luminosa del protagonista y enmarcan la serie mapuche de su cautiverio en nueve capítulos pares -II, IV, VI, VIII, X, XII, XIV, XVI, XVIII, serie que adopta la forma de una relación biográfica. A ella se agrega otra serie, correspondiente a los capítulos impares de la novela, que constituyen la crónica familiar de los Richter, grupo numeroso de encomenderos, en Santiago y en algunas de sus posesiones, que se despliega en nueve capítulos impares -III, V, VII, IX, XI, XIII, XV, XVII, XIX.

La disposición, en Deus machi, ordena las dos series narrativas contrastadas, en que podría pensarse que las palabras Deus, Dios, y machi, curandero o sanador, designan emblemáticamente la contraposición de las dos series: una, la del mundo hispánico y del Dios cristiano y la sociedad chilena criolla y, la otra, la del o de la machi y la cultura mapuche. Esto resolvería, en primera aproximación, el extraño carácter del título con la unión de dos sustantivos.

Una alternativa, entonces, en la interpretación de este título y de la novela, es considerar 'machi' como un adjetivo calificativo de Deus que vendría a significar, desde el borde, la imagen de un dios curador o sanador en oposición a la imagen limitada, por cierto, de un Dios tremendo e irascible y castigador, en afinidad con el sentimiento de Fray Lorenzo y sus percepción de la hibridez o el mestizaje tanto en la experiencia juvenil de su visita a la Catedral Mezquita de Córdoba cuanto de su experiencia como prisionero en el mundo de una reducción mapuche bajo la protección del cacique Anganamón y la amenaza de otros. 
Las dos series narrativas no están totalmente separadas ya que existen referencias de lo representado en una y otra que constituyen cruces de las series. En la serie correspondiente a los Richter y los encomenderos, en conflicto con la guerra defensiva, se encuentran referencias a Luis de Saldivia y Fray Lorenzo en el capítulo III, como enemigos que combaten la esclavitud y el comercio de indios. En el capítulo XVII, se hace referencia a la ausencia de Carlitos en el sur con el Gobernador, y en el capítulo XIX de la serie de los Richter, con referencia al encuentro de Carlos Richter, soldado joven de quince años, con Fray Lorenzo y a su decisión de hacerse misionero. También se hace referencia al viaje a España de Fray Lorenzo con Luis de Saldivia y de los encomenderos para defender ante el rey sus diferentes posiciones.

\section{DISPOSICIÓN}

La disposición de la novela, entonces, se caracteriza por el encuadre de las dos series narrativas, en los capítulos I y XX, inicial y final, con el relato de la experiencia de Lorenzo de Argomedo joven en el capítulo inicial y el sacerdote anciano, cuarenta años después de su experiencia chilena misionera y su cautiverio, en el capítulo final. El primero tiene por escenario la ciudad de Córdoba y por experiencia la extrañeza y la visión del Mihrab, el rincón sagrado de la Mezquita Catedral. El último capítulo le muestra en su retiro en Valladolid, y traza la visión de un sueño complejo en que concurren o desembocan en una suma las experiencias fundamentales de su vida.

En la serie biográfica de Fray Lorenzo, el capítulo I, introductorio, establece el modelo del relato a través de la visita a la Mezquita Catedral de Córdoba del joven Lorenzo, acompañado de su hermana Clara Eugenia.

El modelo describe el cambio experimentado por el joven, una transformación en la que no se reconoce a sí mismo como era antes. Esto ocurre así como el joven acusa el impacto de lo extraño del mundo que contempla, la presencia del mundo árabe y el arte mudéjar, el de la antigua mezquita convertida en catedral, una basílica construida junto a una mezquita, una mezquita de cientos de columnas, encerrada hoy por un muro allí donde fuera originalmente abierta. El joven inexperto no ve, por cierto, como los restos de la iglesia visigótica de San Vicente mártir, destruida por los árabes, yacen bajo la mezquita o sirven para erigir sus columnas, arcos y capiteles, y el narrador lo olvida. Pero de lo que se trata es de un impacto emocional y revelador de algo impensado que le domina como una experiencia transformadora y delirante:

Empezó a vagar por el gran recinto sombrío. Quería seguir sintiendo lo que sentía entre las columnas y en ese silencio. ¡Experimentaba la felicidad de estar comprendiendo por primera vez en su vida el mundo entero! Pero también sabía que no entendía nada. ¿Será esto la beatitud?

Se había puesto de pie repitiendo lentamente unas palabras que hubieran horrorizado al Lorenzo anterior, al que se arrodilló para seguir la misa, pero no le parecían siquiera asombrosas a este que caminaba por la Mezquita y se decía: yo soy Dios; humildemente, mucho más humildemente que cuando antes se arrepentía de sus pecados (11-12). 
La iluminación mística o visionaria experimentada por el joven se extiende en los siguientes términos:

Tenía absoluta certeza de que Dios estaba en él y él en Dios y no reconocía ni las cosas, ni el silencio, ni la luz, ni las sombras ni su propio pensamiento, todo vibraba en dicha y él lo abarcaba en su absoluta unidad y simplicidad. Pero no olvidaba un momento que el milagro le ocurría en un templo construido por hombres que algunos cristianos sentían enemigos, por musulmanes, que no perseguían, ni mataban, ni obligaban a convertirse a los creyentes de otras confesiones y convivían con judíos y cristianos. En un recinto del Dios católico que había mantenido presentes por siglos de piedra a los arquitectos y artesanos musulmanes que lo construyeron para reverenciar a Alá y a su profeta Mahoma (12).

La nueva comprensión del iluminado le lleva a formular conclusiones y escuchar una voz divina que le espanta:

Debía ser posible traer a la fe de Cristo a todos los hombres de la tierra, y todos lo merecían. El mal y el bien existen, pero también al mismo tiempo, no existen, dijo la voz de Dios. Y lo decía sin entonación alguna. Lorenzo se persignó asustado (12).

La matriz que se percibe encerrada en el modelo del texto inicial del relato es la seducción de lo Otro o de la otredad, fundada en el hibridismo como asimilación de los rasgos árabes y de su deformación o malentendido y de los rasgos milagrosamente preservados en tres siglos de occidentalización, de fusión de la Mezquita y la basílica, en una forma cerrada, allí donde la Mezquita carecía originalmente de muros. Es esta seducción la que le induce a manifestar a su hermana Clara Eugenia: "quiero ser misionero jesuita". Confunde su experiencia visionaria del mestizaje y la apertura o incorporación de lo otro desde la perspectiva hegemónica, dominante, con la vocación religiosa declarada. Para cumplir su deseo, la familia se compromete y recurrirá a su cercanía al poder para asegurar la admisión del joven en la Compañía de Jesús.

El relato biográfico del cautiverio de Fray Lorenzo sigue los pasos de la errancia del prisionero en doble tensión. Por un lado, a partir de su aprehensión, por la protección y la acogida que le brindan los caciques Anganamón y Painemal en sus reducciones para arribar al momento de su rescate. Por otro lado, para tomar las medidas necesarias quer sirvan para ocultarse y ser protegido frente a la amenaza de muerte del cacique Narquián que le persigue, quien, atendida la importancia del sacerdote prisionero, quiere darle muerte en un sacrificio ritual. Esto conducirá a un constante movimiento y al descubrimiento o elección de lugares excepcionales para su protección y ocultamiento: el escondite en una ruca ruinosa, en el hueco de un árbol, en una caverna y en un árbol, dentro de un sorprendente lugar ameno. Además, se da el cruce de ríos y particularmente del Bío-Bío, que implica riesgos y cobra vidas en cada tentativa.

Las pausas o descansos de esta errancia permiten al sacerdote descubrir la singularidad de los modos de vida indígena: la vida compartida en la ruca del cacique y sus mujeres, las celebraciones y homenajes en las pirámides mapuches, andamios o palenques, que tienen su antecedente en una descripción que se hace de ellos en Cautiverio feliz de Pineda y 
Bascuñán, y de las que no se tiene imágenes y solo la investigación histórica más reciente ha conseguido imaginar y representar. La experiencia del baño matutino de hombres y mujeres desnudos. El asedio de las mujeres - de Luiftpán y de Aminquir, que le traen de comer- y las tentaciones carnales que le asaltan en el sueño o en la contemplación de los cuerpos desnudos, que concluyen en oraciones y azotes con cilicios en lugares de retiro, culminarán en la 'mañagua', rito mapuche en el cual Aminquir, cubierta la cabeza con la cabeza de una piel de zorro, intercambia su atuendo con el sombrero del fraile, lo que supone la aceptación del sexo. El sacerdote caerá en la 'tentación invencible', caída de la cual se arrepentirá y castigará. Más tarde, cuando Aminquir le pregunta si quiere robársela, como modo de completar el rito y de aceptarla como mujer, el sacerdote rechazará a la muchacha.

La experiencia de Fray Lorenzo se ve marcada, en diversos momentos, por la conciencia de la asimilación de rasgos mapuches y la modificación de su identidad como hibridez o mestizaje. Una experiencia como la suya le marcará para siempre.

El caso que se le ofrece como el de casi completa identificación con el mundo mapuche y rechazo del mundo español y cristiano, lo constituye la figura del indio barbudo, Huencupil, quien resulta ser un un cristiano nuevo, es decir, de antepasados judíos, que fue sacerdote franciscano, de nombre fray Mauricio de Santa María, graduado en Lenguas por la Universidad de Salamanca, con dos doctorados, estudiante de la Cábala, que escapó de Flandes, huyendo de la Inquisición, con el nombre de Pedro Gómez de Alcalá, y fue quemado en efigie en Galicia. Vino a las Indias en un barco holandés, con patente de corso, que lo trajo porque conocía el mapundungun, lo que le permitió entenderse con los mapuches, no así a los holandeses varios de los cuales murieron. Su Cábala, la barba que conserva y el diálogo con Fray Lorenzo señalan su indudable hibridismo.

Diríamos que en la historia de Fray Lorenzo de Argomedo, el fracaso de la guerra defensiva y el retorno a la guerra ofensiva le da el remate sesgado pero ocultamente luminoso del conocimiento y de la caída, mezclada de 'lujuria espiritual'. Y, en su retiro, el recuerdo nostálgico de su pasado misionero y su invariable y oculta condición herética cabalística, mientras se ocupa de escribir la historia de las misiones.

En la crónica de los Richter, familia de militares, encomenderos, comerciantes, hombres y mujeres aparecen apasionados por el poder y la riqueza. La pasión del poder de los encomenderos sintetiza en una frase lo que el relato ordena en una serie de cuadros en que se mueve la ambición, la pugna entre facciones de encomenderos -los Richter y los Mendoza-, o de órdenes religiosas -agustinos, franciscanos, dominicos, contra jesuitas. Pugnas que van desde el diálogo social hasta el violento enfrentamiento callejero. Este poder de los encomenderos se extiende a la mujer sobre sus criados indóciles o irreverentes, y a los niños que juegan con la criada en que cabalgan y a la que azotan con un látigo dejando marcada y lacerada su piel. Cuando se quiere castigar el servicio del indio a su ama infiel y castigar a la mujer engañadora, se le dará muerte secretamente y se abandonarán sus restos en el camino, como ocurre con Catrileo, el indio que acompaña a Catalina en sus visitas nocturnas al Gobernador.

Esta pasión por el poder se modifica en el desenlace sesgado de la crónica de los Richter cuando el joven descendiente, Carlos, con experiencia de la guerra, quiere ser 
misionero y rompe el esquema de la ambición y de la pasión de los familiares inspirado en el conocimiento de Fray Lorenzo. Aunque espera que el poder de su familia favorezca su admisión a la Compañía de Jesús. Mientras la madre, la criolla Ana Luisa, por su parte, se interioriza de los negocios de su marido muerto y experimenta el poder de doña Agueda, su suegra y madre de los Richter, pero coincide con su hijo en la percepción negativa de la esclavitud y del servicio personal que la sociedad de encomenderos defiende fieramente.

\section{CONCLUSIÓN}

El capítulo XX y final constituye la conclusión del relato de Fray Lorenzo y de la novela. Y viene a señalar las consecuencias últimas, que se relacionan con su experiencia primera de la Mezquita Catedral de Córdoba, a los dieciocho años, imagen de la atracción de la hibridez, que mueve su seducción por lo otro y da forma y sentido al relato de su vida.

Cuarenta y un años después de abandonar su experiencia misionera, retirado en su celda de Valladolid, habiendo abandonado la enseñanza de la filosofía y todo aquello que hubiera podido resultar herético y ponerlo en riesgo con la Inquisición, dedicándose solamente a la enseñanza de la gramática latina y de la retórica. Acaba de despertar de madrugada y recupera las imágenes del sueño cargadas de nostalgia, de prodigio, de alegría, que acaba de tener. Contra el Dante y los tristes en el Infierno, estima que la nostalgia es bella. En un juego circular, se produce, mediante el recuerdo, el retorno a la visita juvenil a la Mezquita Catedral de Córdoba, que hiciera con su hermana Clara Eugenia.

En una coherente conclusión retórica, hace el resumen de su vida y el recuento de los muertos en su memoria. En su invariable condición de alumbrado natural, desde la luminosa visión temprana de la Mezquita Catedral de Córdoba, renueva su inclinación, 61 años después, en su retiro de Valladolid, con un sueño sintetizador de su experiencia vital, que es también síntesis del relato de su vida. El prodigio en que culminó su sueño es el siguiente:

De la pared del Mihrab había surgido un mapuche chileno, vestido de blanco y con muchísimo mas de ángel que de indio, aunque estaba armado. Se le acercó como si no tuviera peso, y al llegar a su lado dijo en voz muy clara, pero sin despegar los labios: yo soy el espíritu y soy tú y soy todo. Después comenzó a transformarse a ritmo pausado en Mahoma, en el sol de los incas con figura de hombre, en san Miguel Arcángel, en el dios Júpiter, en la diosa Venus, en Buda, y terminó en una machi deforme, pero cariñosa. Todos repitieron yo soy el espíritu y soy tú y soy todo (208).

Hay aquí una suerte de monismo spinoziano, la concepción de una sustancia única en que todo es uno: el espíritu, tú y todo. O una singular concepción hedonista en la que todos los dioses son el mismo dios. Con hibridismo complejo y singular, sin embargo, como se ve en la propia interpretación, entre la experiencia personal y la lectura de Fray Lorenzo, son divinales en su visión onírica el indio, el sol, Huiracocha, Venus, una Venus morena, Aminquir, y la machi mapuche. 
El mismo Fray Lorenzo con resonancias cabalísticas sui géneris realiza la siguiente interpretación simbólica de los componentes de su sueño con que se cierra la novela:

El indio chileno provenía claramente de su feliz cautiverio allá, al otro lado del mundo, en la ciénaga de Purén, medio siglo atrás, cuando siendo prisionero y vasallo del cacique Anganamón había terminado por reconocer que la vida de los mapuches era más feliz y mejor ordenada que la de los españoles, y que su manera de religión y de honrar a los huéspedes era la alegría, la bebida, la comida y el baile. El sol personificado correspondía a una experiencia unos pocos años anterior, venía de la fortísima impresión que le hizo la ciudad peruana del Cusco, reforzada años después por la lectura de los Comentarios reales de los incas, que releyó en España, porque en las Indias estaban prohibidos y que varias veces le llenó de lágrimas los ojos. El libro le remozó los recuerdos de su llegada al Cusco, donde comenzaban a construir la Catedral sobre lo que fue el palacio del inca Huiracocha y con bloques de piedra roja traídos de otro edificio inca, ¿la habrían terminado finalmente, luego de trabajar tantos años? ¿Habrían destruido más construcciones incas para seguir edificándola? Los demás visitantes de su sueño venían de sus lecturas. La diosa Venus salía de sus libros latinos y griegos, pero esta era morena y tomó la misma posición que tomó el cuerpo de Aminquir, medio siglo atrás, cuando por casualidad se halló junto al río y la vio, desnuda, al amanecer, entrando en el agua con otras muchachas indias para su baño matutino. Del mismo tiempo provenía la última, la machi mapuche, salida también de los tiempos de su cautiverio que podía recordar detalle a detalle, como si hubieran ocurrido el día anterior (208-9).

El mensaje que le dieron las apariciones ponía en unas pocas palabras los escasos momentos realmente significativos y felices de su larga existencia, esos mismos que le habrían acarreado terribles problemas si alguien más los hubiera sabido (209).

Cerca del pensamiento de la Cábala y Huencupil, deja, asaltado de temores, una escritura secreta, oculta en un tomo de la Summa Theologica, de Santo Tomás de Aquino, aunque -son las frases finales de la novela- "Se le había ocurrido, medio en serio, medio burlándose de su locura, que ojalá no destruyeran sus papeles y alguien, algún día, consiguiera descifrarlos" (212).

La escritura secreta o cabalística, según propone Huencupil, el mapuche barbudo, permite múltiples lecturas de lo mismo así como las letras o las palabras se reordenan. El lector podrá libremente, desde ese punto de vista, leer otra cosa allí donde nosotros leemos el mundo de Fray Lorenzo y la seducción de lo otro y el mundo de los Richter y la pasión del poder. Dos visiones diferentes y contrapuestas que derivan de la imposición de la guerra defensiva y de su fracaso y del contacto de dos mundos extraños, de su rechazo y de su inevitable influencia mutua. 